\title{
A noite dos viúvos
}

David Oscar Vaz

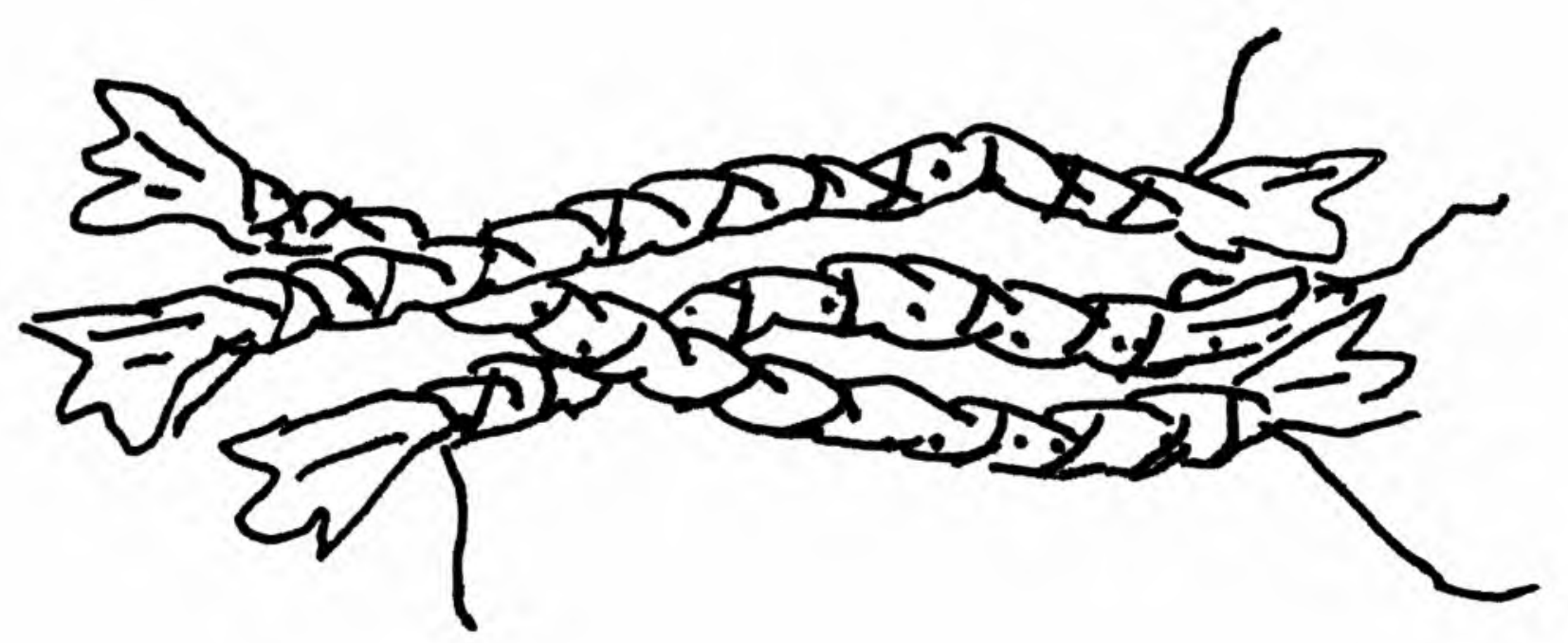




\section{Lá em cima do piano}

Tem um copo de veneno

Quem bebeu mor...reu

E o culpado não fui ...eu

E o escolhido foi vo...cê!

É o mês das bruxas e de cachorro louco. Um professor amigo de Fernando acrescentaria também: e de crise política. Outros ainda... Não, chega; adicionar outras variedades de tragédias e fatalidades a um mês tão aziago seria torná-lo mesmo indistinto em relação aos outros. O certo, o previsível até, é que Fernando nunca deixou de guardar qualquer referência a este mês depois da tragédia, da única tragédia que agosto realmente lhe deu. Havia no dia 24, então, uma mística muito própria. Quando folheavam, ele e Teresa, um livro de fotografias sobre Pompéia, no primeiro aniversário sem a presença de Raul, ali deu, pela primeira vez, com a intromissão desses dois algarismos definitivamente associados. Ali surgiram o 2 e o 4, para sempre 24, numa legenda embaixo de uma fotografia, e este número trazia um ar irônico e perverso, como uma pessoa inconveniente que surgisse num momento muito grave: ... e o Vesúvio entrou em erupção aos 24 de agosto... Fernando pasmou, súbito, como se visse brilhar, através dos dois algarismos, aqueles olhos sempre muito negros e sorridentes de Raul. Num segundo depois, se refez, se refez um tantinho, o suficiente para espiar de rabo de olho se Teresa sentira o mesmo calafrio que ele. Pareceu-lhe que não; ou não reparava na data, ou fingia não tê-la visto, ou, quem sabe, este número não tivesse a mesma importância que tinha para ele. Olhava antes fixa, tomada que estava, para a fotografia em que a cor sépia predominava enfatizando o silêncio dos séculos em que um homem, fossilizado na sua cama e num gesto eterno e inacabado, pensou Fernando, esperasse pacientemente ser resgatado. Depois descobriu, uma revista na sala de espera do dentista o recordou, que Getúlio havia deixado a vida para entrar 
história, naquele seu suicídio premeditado, nos mesmos precisos dia e mês.

Soube em certa ocasião em que consultara um amigo sobre um bom livro para

ler, que a data era também a do nascimento de Julio Cortázar, cuja obra

Fernando nunca leu, nem antes nem depois dessa conversa e, portanto,

nunca pôde compreender o que queria dizer-lhe o amigo quando observou

que sempre se poderia encontrar na vida de um cara comum um episódio que servisse de matéria a um conto de Cortázar.

E era a noite do dia, e Fernando só poderia ser encontrado na casa do

Horto. Ainda que quisesse se esquecer do calendário, uma certa exaltação no sangue o lembraria a aproximação do dia; como agulha imantada, inevitavelmente atraída pelo Norte, iria para a casa do Horto, como chamavam a casa em que um dia ele e Teresa em vão aguardaram, com bolo de chantilly com morangos, a chegada de Raul e Lucília. E Fernando chegou, e foi recebido com a mesma gentileza por tia Teca, que o abraçou comovida e o levou, em seguida, com orgulho infantil e mal disfarçado, para ver a mesa arrumada. Àquela hora, já havia preparado, como obedecendo a um secreto cerimonial, os salgados e os doces ali dispostos com capricho, e a coca-cola e o vinho na geladeira, e tudo numa quantidade sempre muita para tão poucos, como se esperasse que alguém mais pudesse aparecer.

Tia Teca faria companhia a eles até às 2 I horas, quando, impreterivelmente, subiria para seu quarto, e nada a faria descer de lá, nem se a música estivesse alta, o que não ocorreria, nem mesmo se ouvisse gritos.

Voltaram depois para a sala, què Teresa já estava para descer. Tia Teca foi preparar o capuchino, e Fernando ficou olhando para ver se a sala teria sofrido alguma alteração. Nada, tudo como sempre fora. Sobre o piano, a foto de Raul ainda ensaiava um sorriso, colocada ali com grande beijo de Teresa no dia em que anunciaram o casamento aos amigos. Na estante, ainda havia os livros de que Raul mais gostava, seus livros de arquitetura, de fotografia, que foram trazidos por ele como uma primeira remessa da mudança que se completaria com o matrimônio, 
sonho que também ficou para sempre no projeto. Ali se reuniram tantas vezes para jogar buraco, ou para fazer a brincadeira do copo que tanto apavorava Teresa e também Lucília, quando esta mais tarde passou a freqüentar a casa. Fôra naquele sofá, quando uma noite Teresa tocava um noturno de Schobert, que Raul confessou ao amigo o medo que sentia em se casar. Amava-a demais, não havia amante no mundo como ela, então tinha medo, receio de que com o casamento... Fernando não soube o que dizer, e não disse nada, ou disse sem dizer, o que dava no mesmo, e fizeram depois silêncio, um silêncio longo, pactuado, deixando-se levar cada qual para a sua cidade submersa embalados pelas notas do noturno que saíam dos dedos de Teresa. Fernando sabia que decisivos momentos de sua vida estariam ligados a esta sala. Fora ali que vira Teresa, na noite de aniversário de Raul, dirigir-se apreensiva para atender ao telefone, pronta para dar uma bronca no já agora noivo, meio a sério meio de brincadeira, pelo atraso do aniversariante no dia de sua festa e, sem nada dizer, virar-se pálida com o fone ao ouvido, murmurando, depois de um breve silêncio, algumas palavras em um dialeto absolutamente desconhecido, desabar sobre uma poltrona para, em seguida, olhar para tia Teca, para ele, e cortar a noite com um grito. Depois, tendo quase que arrancarlhe o aparelho da mão, ouvir uma voz desconhecida e quase impaciente se ele era da família, precisavam de alguém da família. Fernando sabia que também os melhores momentos de sua vida estariam ligados a esta sala, como estas visitas em que ele era o esperado e que jamais, diferentemente de Raul, deixaria de vir, reforçando a cada ano a convicção quase ingênua que vigia na casa do Horto, de que o raio da desgraça nunca cai duas vezes da mesma forma. Momentos felizes como cada aparição de Teresa vindo para recebê-lo, como agora quando Fernando olhou, e ela já estava descendo as escadas. E sorria, com aqueles mesmos lábios grossos que um dia beijou a fotografia de Raul antes de colocá-la sobre o piano.

Teresa o beijou, pegou suas mãos e olhou para ele com muito carinho.

- Que bom que veio! 
Talvez pretendesse dizer também que ele devia vir mais vezes, assim Fernando entendeu e pagou cada gesto da amiga com outro equivalente, talvez até com um pequeno saldo a mais.

— É bom te ver tão bem, e bonita!

Neste momento, tia Teca entrou com a bandeja com capuchinos.

Colocou-a sobre a mesinha e foi buscar a travessa com as comidinhas, conforme disse. Teresa colocou um cD do Duke Ellington, que era sempre com que começavam a falar de Raul. Os três juntos agora e, deve ter sido um equívoco da velha, mas um equívoco que se repete pode se tornar um assombro. Tia Teca ofereceu bolo de fubá para Fernando. Tantos garçons erram de pratos e de fregueses, por que uma senhora com idade avançada não poderia errar também? Mesmo que já fosse uma tradição entre os amigos o fato de Fernando detestar bolo de fubá,

o acontecimento seria certamente irrelevante, não fosse a maneira como a senhora se dirigiu a ele.

- Tome este pedaço, Raul, que está do jeito que você gosta!

Fernando olhou para Teresa, mas Teresa olhava para outra coisa e pareceu não ter percebido o equívoco, ou fingiu não ouvi-lo. Como a mulher trocou-lhe o nome por duas ou três vezes, enquanto insistia que ele apanhasse o bolo, Fernando não teve outra saída senão corrigi-la:

- A senhora se enganou, Tia Teca, quem gostava de bolo de fubá era o Raul.

Tia Teca olhou para Fernando com se não entendesse a correção, mas, logo em seguida, teve que pousar a xícara na mesinha porque, do contrário, o tremor repentino nas mãos a faria cair. Levantou-se e, com a voz trêmula, disse que precisava buscar algo na cozinha. Durante todo esse momento, Teresa estivera lendo absorta alguma coisa interessante na ficha técnica do CD. Fernando pensou que seria dolorido para Teresa ter que admitir que tia Teca não estivesse tão bem quanto antes, ou muito mais dolorido seria ter que falar do próprio engano.

Fernando jamais tocava no nome de Raul, preferindo, tendo desenvolvido toda uma técnica de passar à margem, esperar sempre que Teresa o fizesse. 
Depois do aniversário em que ninguém pôde provar do bolo de chantilly com morangos, Fernando rareou mais as visitas; às vezes ligava para amenizar a solidão, a dele e a dela. Numa dessas vezes, em que a voz ouvida tinha a suma importância dos assuntos banais que conversavam, Fernando informou a Teresa que haviam programado $U m$ corpo que cai para uma das retrospectivas de cinema da cidade. Há tempos Raul havia comentado desse filme, e o amigo, agora, tendo-o achado na seção de cinema do jornal, sentia-se na obrigação de falar dele. Fernando não poderia convidá-la, se ela o fizesse... Não fez, e ele temeu ter pisado desastradamente numa ferida ainda muito viva. No sábado à noitinha, lá estava Fernando chegando atrasado e perdendo a abertura do filme. Não poderia dizer quanto tempo depois, num momento de um reflexo da luz, pensou ter visto Teresa a quatro fileiras adiante. Teve que confirmar três vezes. Era ela. Por que viria? Pelo mesmo motivo que ele, certamente. E se veio só é que não queria sua companhia. O cinema, a partir de então, tinha uma atração a mais. O que ela estaria vendo?

O que seria ver pelos seus olhos? Terminada a projeção, Fernando a seguiu. Ela tinha os cabelos presos feito rabo de cavalo e a pinta na nuca poderia ser vista se Fernando se aproxima-se mais. Ele preferiu a distância, era um James Stewart atrás de uma Kim Novak, melhor, um personagem de si atrás de uma personagem dela caminhando até o estacionamento, para onde ele a viu entrar e de onde ele a viu sair, pensando certamente no outro com quem ela nunca havia assistido ao filme.

E quando Teresa levantou os olhos da fotografia de Duke Ellington na capa do $\mathrm{CD}$, perguntou:

— Você sente saudades de Lucília?

E foi uma pergunta admirável porque foi a primeira vez que Teresa perguntou de Lucília. E depois de todos esses anos, Fernando não estava mais preparado para ela. Só namoravam havia três meses antes daquele fatal aniversário. E se ele não tivesse pedido a Raul para apanhá-la em casa, para dar-lhe uma carona, já que ele chegaria tarde vindo direto do escritório, talvez ainda estivessem vivos, pois Raul 
não precisaria ter corrido tanto por estar atrasado e não ter cruzado a frente daquele clandestino caminhão frigorífico, cujo motorista, apesar de nesta noite não estar bêbado, não conseguiu desviar a tempo seu veículo da formidável colisão. E o que poderia Fernando responder? Que Lucília havia lhe prometido, ao telefone naquele tarde, que, depois da festa de aniversário, eles teriam uma noite de amor com muito sexo, como ele gostava e ela também, mas que um caminhão frigorífico havia frustrado a promessa que ele tanto aguardava e esfacelado o desejo com um estrondo de metais retorcidos traduzido momento depois no grito lacerante de Teresa? Ou que ele sentira muito a morte de Lucília, com quem fizera amor algumas vezes, e isto aumenta em anos uma amizade cheia de carinhos, mas que sentiria muito mais se no lugar de Lucília perdesse Teresa? Ou, mas isto ele também não poderia revelar, que, quando na saída naquele sábado do cinema, ele, por um instante, pensou ver caminhando à sua frente não Kim Novak, não Teresa, mas uma mistura de Teresa e Lucília, já que esta costumava ter o hábito de passar o indicador por sobre a orelha, mesmo quando tinha os cabelos presos, como fez aquela, e também aquele jeito de andar balançando gostosamente o corpo quando caminhava, que Fernando ficou tentado a se aproximar, abraçá-la por trás, como gostava de fazer com Lucília e como desejava fazer com Teresa? Ou, e pôde dizer isso porque isso era também verdade:

- Sinto saudade dela, mas não dela, de um tempo em fomos aqui alegres. Aqui nesta sala...

- E Raul era então o sol que nos aquecia — e Teresa, quando disse isso, já estava em pé próxima da janela olhando para o nada lá fora.

Fernando, por um momento, sentiu de longe assomar a tentação de dizer o que lhe dissera o cabo da PM no dia do acidente para consolá-lo, mas isso ele somente para si guardaria.

Tia Teca voltou finalmente com outro pratinho e com refrigerantes, sentou-se numa poltrona com seu tricô próxima do abajur, porque não era tão 
iluminada a sala e ali ficou devotada ao seu trabalho com agulhas, participando da discussão com um mover de cabeça ou, no máximo, uma frase curta de concordância. Teresa é que era a alma perfumada da sala, usava um vestido preto, levemente agarrado ao corpo, decotado em $\mathrm{V}$ na frente e nas costas, com a diferença que aqui o vértice do $\mathrm{V}$ era mais profundo, se tivesse que deixar ambiente tão agradável teria que, forçosamente, jogar o xale que estava agora pendente sobre o piano às costas, ação que só iria lhe dar outras graças. Ao invés disso, foi até a estante, apanhou um livro e veio se sentar mais próxima de Fernando. Ver Teresa assim tão perto era mais que uma graça, concorriam com a boca seus olhos castanhos, cujos cílios longos e fartos tornavam ainda maiores; eram como um par de convites destinados a um só convidado e chamavam à festa, à festa de ver com ela o que trouxera da estante, o que Fernando aceitava feliz, ainda que intimamente soubesse que festa mesmo grande estava no próprio par de convites e nos seus arredores. Teresa abrira mais uma vez para Fernando o livro de projetos de Raul, ali estavam seus desenhos de construções pretensiosamente ousadas, quase absurdas, com um Escher oculto, assinados com uma letra firme e miúda, ali se encontravam também alguns retratos a carvão traçados com muito apuro, os de Teresa eram mais numerosos, havia até um de Lucília, talvez o mais infeliz, pois a expressão fazia lembrar uma coruja. Para Fernando, Raul tornara-se um pretexto e uma esperança, através dele chegava a Teresa, através dele esperava paciente, quem sabe, que ela viesse pelo seu caminho e o encontrasse.

De quando em quando, Fernando olhava para a mulher tão próxima e tão distante. Assim de perfil, parecia tão frágil, tão frágil que ele sentia o dever de protegê-la. Ao mesmo tempo, uma mulher decidida que quis ver o corpo do namorado morto naquela noite, a noite que nunca terminou. E Fernando a levou, teve que levá-la, ele mesmo precisando de amparo aparando-a, atravessaram frias salas, suportaram funcionários enfadados com a rotina, compartilharam a dor com a irmã e a mãe de Raul que lá já os aguardavam. Fernando teve apenas um mo- 
mento em que pode chorar só a perda do amigo, quando se afastou para um dos corredores do IML, instante breve, pois logo chegou um cabo da PM para lhe informar alguns procedimentos e dar-lhe uma informação que era uma espécie de analgésico duvidoso. Depois, quando foi ver o local do acidente, Fernando pôde imaginar, no momento e muitas e muitas vezes depois, relembrando a posição dos destroços do que segundos antes era um carro novo e bonito e do caminhão, como tudo havia se passado. E como num filme, Fernando viu Raul vindo daquela avenida, de onde apontou em ávida corrida, talvez Lucília risse, sim ria, excitada com a situação e com gosto de também excitar Raul, Lucília ria, ao mesmo tempo, do outro lado, vinha também um caminhão frigorífico, não em natural andadura de paquiderme, mas em velocidade de monstruoso estouro, vindo à toda na perpendicular para colhê-lo na próxima esquina, e assim foi, tudo rápido, risos seguidos de gritos e tudo levado para sob os escombros da impossível freada em ruídos e fúrias de ferros selvagens. Até podia imaginar que momentos antes, tudo fora tão oposto àquela agitação. Raul chegando para apanhar Lucília, ela lhe dando os parabéns, ele agradecendo um tanto envergonhado, não deviam se atrasar, mas talvez desse tempo para tomar uma água, quem sabe uma bebida. Raul não devia ter bebido nem uma dose nem duas, sabe-se lá quantas foram, talvez tudo fosse evitado, inútil pensar assim, e lembrou-se mais uma vez das palavras do cabo da PM tão reveladoras e tão inúteis ao consolo.

Depois de tudo pelo que Teresa havia passado, era bom senti-la ao seu lado (recuperada?). Duke Ellington havia sido substituído por Brahms e, nesta hora, ela abria um outro livro querido de Raul. Fernando a olhava comovido, com ímpeto de beijá-la. Conteve-se. A dor da morte a trancara no quarto e a fizera chorar por uma semana, dos sonhos despertava às vezes aos gritos e prantos, tanto foi, que tia Teca passou a dormir com ela um tempo. Ainda agora tinha uns silêncios longos, uma ausência que por vezes confundia a tia, uma quase perigosa calma. Não demorou muito tia Teca recolheu suas coisas para subir. 
- Não quer um golinho de vinho antes de dormir, tia.

- Obrigado, minha filha, você sabe o que disse o médico... agora vocês, bem, vocês é que podem abusar - e voltando-se para Fernando - Cuide dela, meu filho, e aproveite a noite.

Depois que tia Teca subiu, Teresa serviu vinho. Fernando apanhou a taça e ergueu-a.

- A nós!

-A nós!... Sempre!

Enquanto beberam, Teresa falou da música, explicando uma complexidade do trecho que ouviam. Beberam mais, e ela então falou da lua, do frio e do luar. Num dado instante, o vinho que a relaxara, as pernas afastadas e as costas afundadas na poltrona, acumulou-se no canto da boca, ela sorriu, engasgou e pegou a rir. O que deixou Fernando maravilhado, há quanto tempo não a via assim rindo gostosamente, e ela, ao recuperar-se sem pressa nem cuidado, notou o encanto nos olhos dele. Depois voltou a falar da lua, uma lua de agosto e seu luar. Por associação, por certo, lembrou-se de bruxas e coisas assim. Bebeu um outro gole:

- Você faz tempo que não faz a brincadeira do copo?

A pergunta surpreendeu Fernando. Raul é que gostava tanto daquilo, as letras do alfabeto recortadas em quadrados que eram colocados em círculo; todos à volta com o indicador em cima de um copo emborcado girando no centro de uma mesa. "Alguém está empurrando o copo?" Ninguém estava. "Nem um espírito empurra, sua bobinha, dizia Raul a Teresa, é apenas o inconsciente de alguém." Mas da última vez, ninguém contava com o pânico, o medo que tomou conta do mais cético. "Há um morto nesta sala", escreveu o copo. Raul riu e perguntou quem era. Um segundo depois, o copo se espatifou contra a parede e a brincadeira estavadesfeita numa agitação de descarga elétrica espalhada no ar. Todos tentando acalmar Lucíclia que andava que desandava sem rumo pela sala, pois o nome que o copo havia escrito era o de uma prima sua que morrera no mês anterior. Não teve 
explicação lógica que a convencesse, e nunca mais fizeram a brincadeira. Agora vinha Teresa com esta pergunta, que era quase um convite. Gostaria de ver de novo, então, sufocando o medo, o copo girando e fazendo aquele ruído do vidro sobre o tampo de madeira da mesa, deslizando medonho e escrevendo: "há um morto nesta sala"? E que se perguntasse quem era que estava ali, o copo percorrendo sobre o tampo, de letra em letra, decisivo, iria formar o nome esperado: Raul? Era isso? Fernando então respondeu:

- Nunca fiz e nem quero mais fazer.

Tereza sorriu e, notou Fernando, tinha no sorriso um ar que beirava o maligno:

— Você tem medo!

Ela aproximou-se dele, sorriu de novo e deu-lhe um beijo na boca, mas breve, quase nada estiveram unidos os lábios, havia simplicidade no gesto, mas o gesto em si é que era inusitado. Teresa levantou-se e foi indo ao piano, talvez por efeito do vinho, naquele jeito balançado que lembrava Lucília. Sentou-se, levantou a tampa dos teclados e o noturno de Schubert os revisitou. Da outra vez Raul estivera ao lado de Fernando. Não há amante no mundo como ela. Mas então por que? Por que aquela noite... e a lembrança outra vez, tudo começou de maneira tão diversa de qualquer dor que era impossível que se previsse a tragédia, Raul chegando para apanhar Lucília, ela o cumprimentando feliz pelo dia e o convidando para uma bebida, não devia, depois do terceiro copo, quem sabe o que se faz depois do terceiro copo com o estômago vazio? E mais tarde Fernando no corredor do IML, no único momento que teve para chorar sozinho, o cabo aparecendo para lhe informar dos procedimentos, a família fica tão chocada que é sempre bom algum amigo para ajudar. Disse que já haviam feito a autópsia, notando por fim sua tristeza, disse-lhe o cabo:

- Sei que não serve para consolo de todo, mas se eles tinham que morrer mesmo, tiveram antes uma compensação — um segundo de silêncio e concluiu 
- fizeram sexo. Verdade, o legista confirmou. Quando for a minha vez, amigo, que seja pelo menos assim!

O cabo evidentemente não sabia que estava falando com o namorado de uma das vítimas. Fernando ficou ali encostado à parede. Não chorou porque para alguns há uma dor que vai além de qualquer lágrima, depois vai passando, e passa, e fica no lugar uma coisa mais calma, uma coisa que ainda precisa de nome e que, portanto, só pode ser dita por outras palavras. Há coisas que só se dizem com uma história.

Não há amante no mundo como ela. Raul não estava ali para dizer isso outra vez, mas Teresa estava, tocando, e seus cabelos roçando nas costas ao som do triste noturno de Schubert. E algo aconteceu então, o som deixava de ser triste ao balanço que imprimia à música os dedos de Teresa, como se dentro da música houvesse uma outra música menos triste, mais sensual. E era com esta que Teresa o abraçava e o puxava para si e, por isso, num dado instante, Fernando se levantou e foi até ela ao piano. Colocou suas mãos sobre seus ombros; Teresa não parou de tocar, mas inclinou a cabeça um pouco para trás para encostar-se nele e não escondeu o prazer de sentir o calor ao toque de seu corpo. Fernando foi descendo as mãos, abaixando-se enfiou a cara de leve nos seus cabelos, depois os apanhou, descobrindo a pinta na nuca e ali depositou um beijo, longo. Ela então foi se levantando, abandonando a música e deixando que ele a abraçasse por trás, enconhando-a e ela tremendo um pouco e roçando onde tateava a bunda um grosso desejo. Então Teresa levantou um pouco a saia para que ele acabasse de erguê-la e curvou-se um pouco fazendo surgir a calcinha também preta e rendada que apareceu vistosa, mas durante um segundo, para em seguida escorregar pernas abaixo. Ela então curvou uma das pernas apoiando o joelho sobre as teclas do piano e não se importando com barulho, uma das mãos caiu sobre outra parte do teclado e assim convidava-o a penetrá-la. E foi o que ele fez em seguida, e foi como se esperassem há tanto tempo por aquilo, como se um gesto interrompido, 
congelado há séculos por lava vulcânica, quebrasse a crosta que o envolvia para finalmente ser concluído. Teresa gemia ao sabor da maré do desejo indiferente ao sono de todas as tias do mundo. No momento seguinte, Fernando debruçou-se sobre ela para chegar-se mais ao calor de seu corpo, e viu, neste instante, o que quase o arrancou de si, que Teresa olhava, com lascivos olhos semicerrados, para a fotografia de Raul a apenas alguns centímetros de seu rosto. Há um homem vivo nessa sala. Esta seria a tradução de seu pensamento e deitou o porta retrato com a foto de Raul para baixo. Teresa viu o gesto e apenas fechou os olhos entregando-se. Fernando também fechou os seus e gozaram, gozaram... Assim ficaram por um tempo, depois, ainda com os olhos fechados como uma cega que tateia um rosto amado, ela virou-se para ele e o beijou, beijaram-se longamente e só não foi mais longo o beijo porque Teresa começou a chorar e abraçou-o forte.

- Hoje choro porque estou feliz - justificou.

Fernando, que também estivera de olhos fechados, abri-os e pode ver, não sem algum horror, que o porta retrato voltara a posição original e Raul o olhava com aqueles seus olhos que sorriam. Ela o teria levantado já que os mortos não se levantam sozinhos. Desfez-se do abraço dela quase com carinho. Arrumou-se para sair, ela também não disse nada, seguiu-o apenas até a porta. Fernando desceu os três degraus que separavam a casa do jardim. As luzes de fora estavam apagadas, a lua silenciosa o olhava do céu e o luar, o luar em toda a parte. Não pode virar-se e dizer adeus para Teresa que havia parado com xale aos ombros no quadro da porta, teve receio de ouvir um até breve, teve receio de que ao dizer até breve ela o chamasse pelo o nome de um morto. 


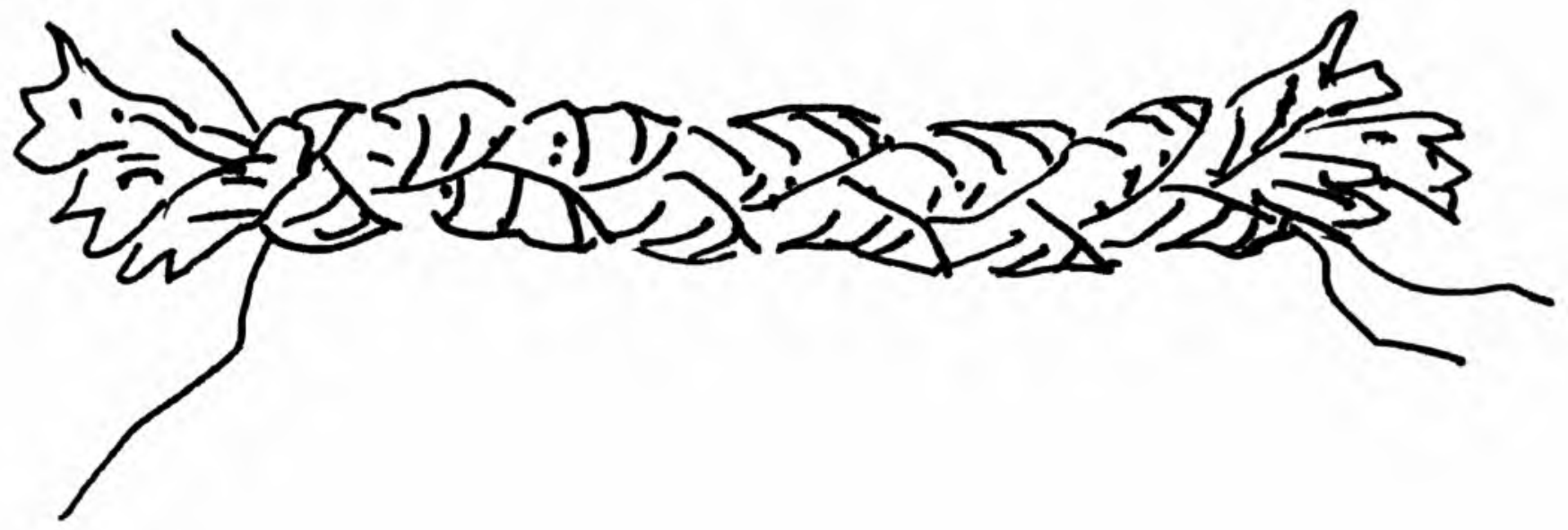

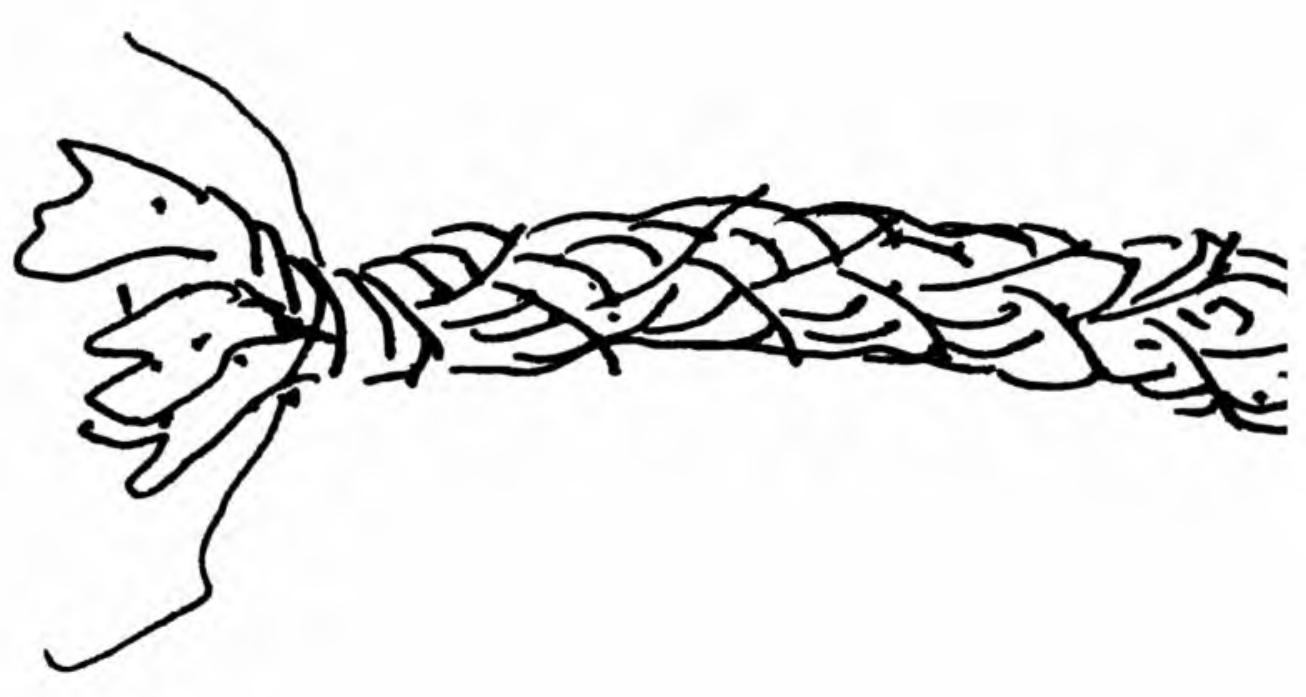



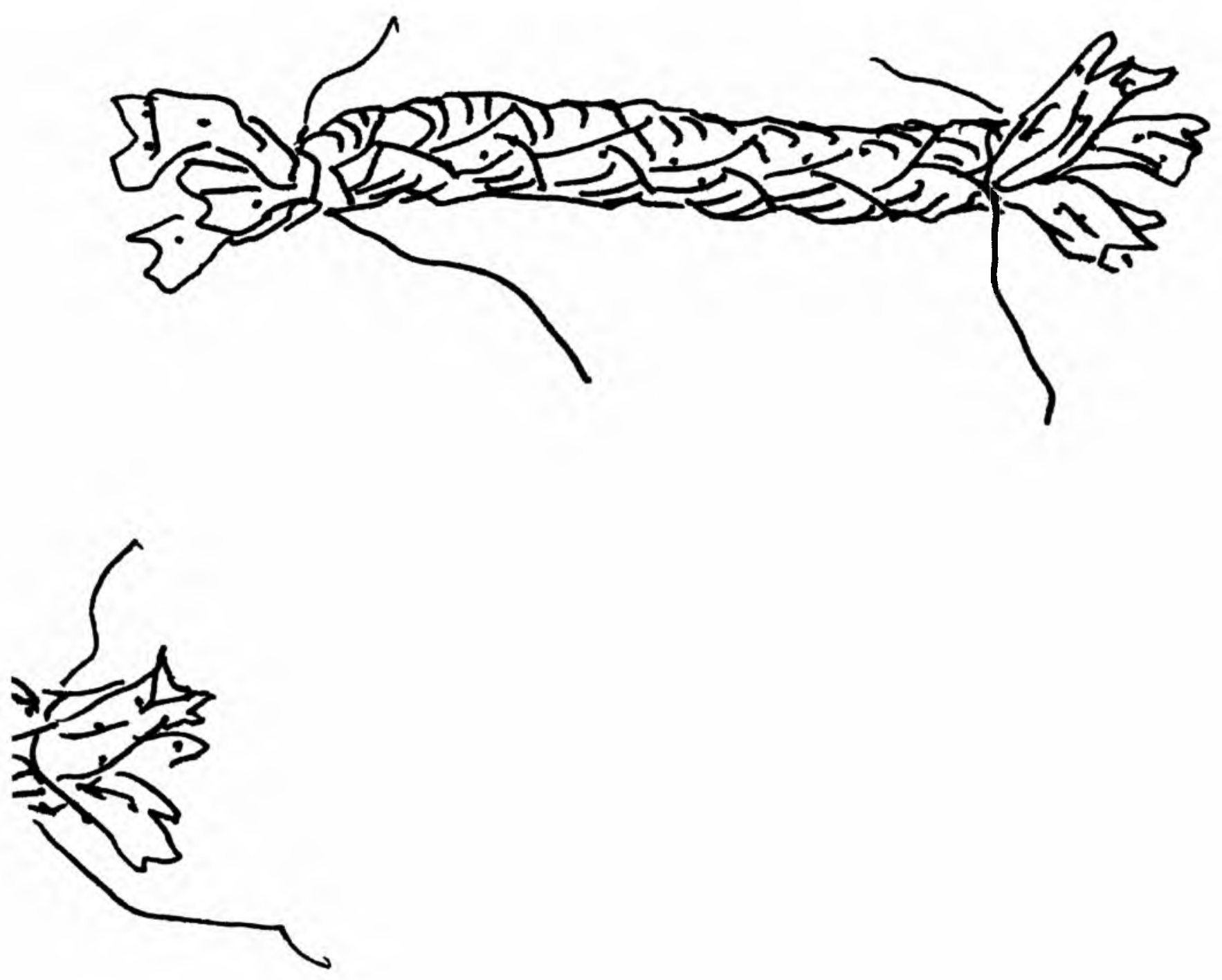